\title{
Development of Hardware-in-the-Loop Simulation System to Test HVDC Controllers
}

\author{
Ho-Ik Son, Hyeong-Jun Yoo, and Hak-Man Kim* \\ Incheon National University \\ hmkim@incheon.ac.kr
}

\begin{abstract}
Recently, it is anticipated that high voltage direct current (HVDC) systems will be applied to interconnection between the mainland and off-shore wind farms, power flow control for alternating current $(A C)$ power girds, long distance transmission, and interconnection of the supergrid. For these reasons, controllers and protection systems as subsystems for the various HVDC system applications have been developing. It is difficult to test them in the real HVDC system practically because the HVDC system is a huge system. In this paper, a hardware-in-the-loop simulation (HILS) system based on the eMEGAsim real-time digital simulator (RTDS) supplied by OPAL-RT. CIRGE benchmark HVDC system is modeled and a CompactRIO-based controller of the HVDC system is designed. The controller is tested in the HILS system to show the control performance.
\end{abstract}

Keywords: CIGRE benchmark high voltage direct current (HVDC) system, controllers of HVDC system, the hardware-in-the-loop simulation (HILS) system, CompactRIO-based controller

\section{Introduction}

Recently, interests in high voltage direct current (HVDC) systems has been growing due to interconnection between the mainland and off-shore wind farms [1-3], power flow control for alternating current (AC) power girds [4-6], long distance transmission, and introduction of the supergrid, which is a large scale power grid interconnected between national power grids [7-8]. For these reasons, development of controllers and protection systems for the various HVDC system applications has been studying.

The HVDC system is composed of many subsystems such as controllers and protective systems. Since testing the HVDC system or the subsystems of the HVDC system requires a lot of costs and constraints, it is difficult to test them in the real HVDC system practically. A technique to solve the problems is the hardware-in-the-simulation (HILS). The technique uses a real-time digital simulator (RTDS) to emulate a plant and the tested subsystem, where input and output signals are telecommunicated between the RTDS and tested subsystem [9-10]. For this reason, the HILS technique has been applied to develop and test controllers and protective systems for power grids.

In this paper, controllers of the rectifier and the inverter of the CIGRE benchmark HVDC system based on the CompactRIO, which is a general-purpose controller and is designed using the LabVIEW [11], are developed. In addition, a HILS system is develop using the eMEGAsim RTDS supplied by OPAL-RT to emulating the CIGRE benchmark HVDC

${ }^{*}$ Corresponding Author 
system as well as the developed CompactRIO-based HVDC controllers to test performance of the controllers.

In Section 2, the concept and applications of the HILS system are introduced. The backgrounds of the CIGRE benchmark HVDC system and its controllers are described in Section 3. In Section 4, the implemented HILS system and the CompactRIO-based HVDC controllers for this study are explained. The CompactRIO-based HVDC controllers of the CIGRE benchmark HVDC system are tested in the HILS system and the performance of the controllers is analyzed in Section 5. Finally, we conclude in Section 6.

\section{HILS System}

HILS is a technique to develop and test complex and/or large scale systems. The HILS technique has many advantages to overcome restrictions on test spaces and to save costs and times for test and development [12-14]. Initially, HILS has been used for analysis and test of costly systems such as automotive system, aircraft system and so on [15-16]. Since then, the development of the HILS has been continued to improve its performance. For these reasons, application areas have been expanding into various areas such as robotics, power electronics, and power systems.

In the HILS system, a plant is modeled and is embedded in a RTDS. The tested subsystem receives input signals from the RTDS and transmits output signals to the RTDS through the interface. As a result, the tested subsystem can be tested in the laboratory like the real environment.

\section{HVDC System}

\subsection{Components of HVDC system}

Figure 1 shows the CIGRE benchmark HVDC model. The 6-pulse converters are connected with two transformers whose winding methods are $\mathrm{Y}-\Delta$ connection and $\mathrm{Y}-\mathrm{Y}$ connection, respectively. AC filters include capacitor banks and harmonic filters to compensate reactive power and to eliminate specific harmonics. The DC transmission line is modeled by an equivalent line of T-type including resistances, inductances, and a capacitance. HVDC control parts are composed of the master controller and pole controllers.

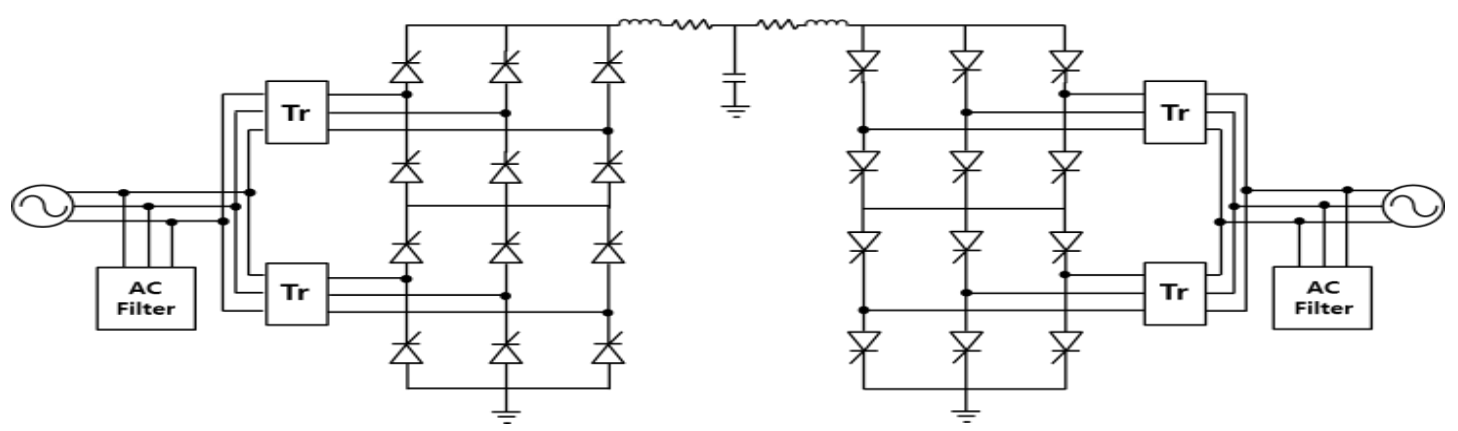

Figure 1. CIGRE Benchmark HVDC Model

\subsection{Operating Principles of HVDC System}

The CIGRE benchmark HVDC system uses thyristors as switching elements. In a practical HVDC implementation, it is required for thyristors to be connected in series to obtain the 
desired voltage rating and operating characteristics. Thyristors can control turn-on point only by firing angle $\left(\alpha^{\circ}\right)$. Figure 2 shows the equivalent circuit of the rectifier side [17-18].

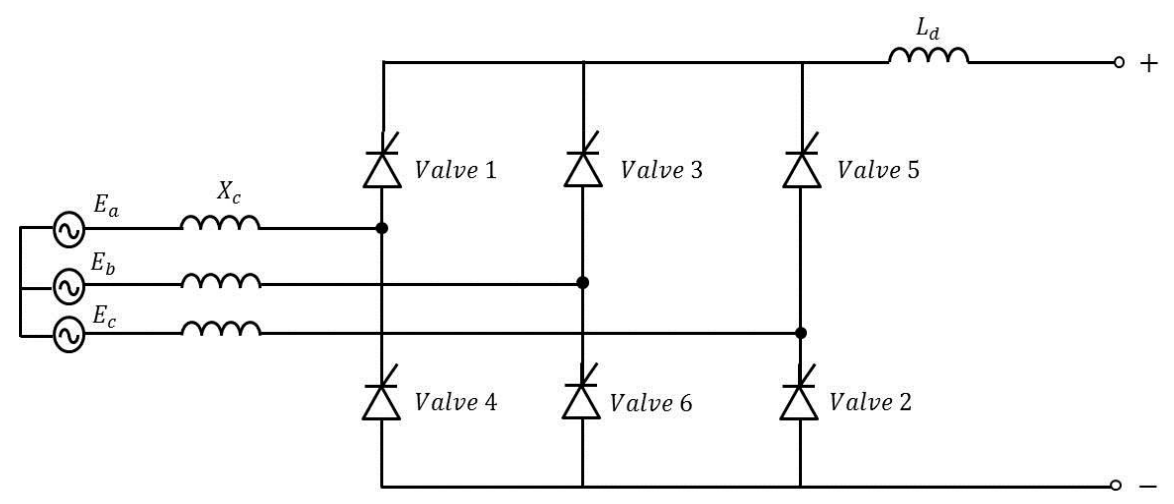

Figure 2. The Equivalent Circuit of the Converter

Figure 3 shows the waveforms of the commutation voltage with firing delay. Each valve of upper row conducts when voltage of each pole is more positive than the voltage of the other poles. When a firing angle $\left(\alpha^{\circ}\right)$ is applied as control signal of thyristors, commutation voltages, which are equal to line-to-line voltages, are reduced somewhat. Thus, Average DC voltage is reduced due to the firing delay.

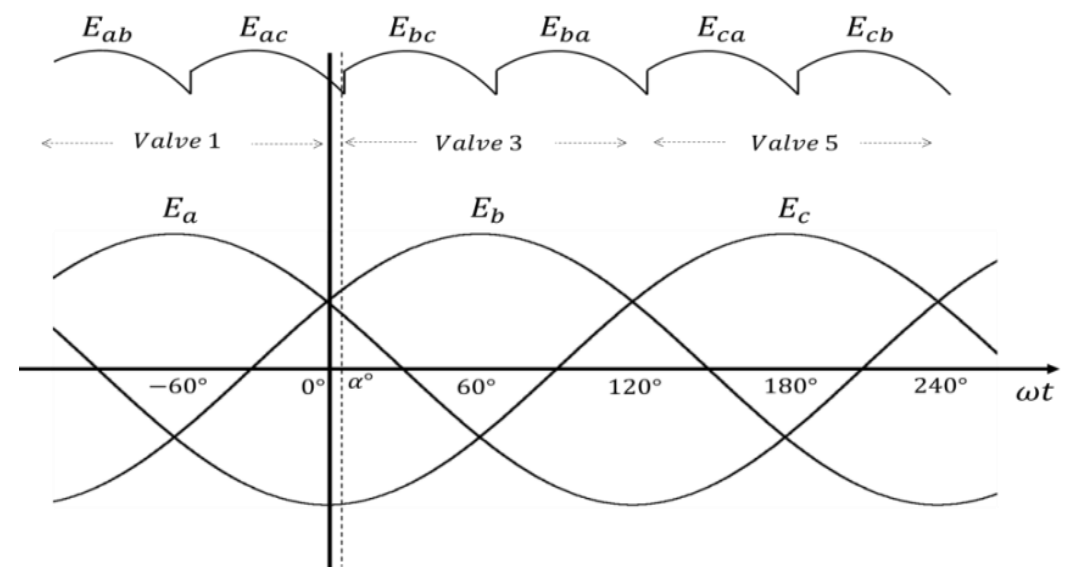

Figure 3. Commutation Voltages with Ignition Delay

Using line-to-ground voltages such as $E_{a}, E_{b}$, and $E_{c}$, shown in Figure 3 and the amplitude of three-phase voltages, $E_{m}$, the DC voltage can be calculated by the equation (1).

$$
\begin{aligned}
V_{d r} & =\frac{3}{\pi} \int_{-60^{\circ}+\alpha^{\circ}}^{\alpha^{\circ}} E_{a c} d \omega t \\
& =\frac{3}{\pi} \int_{-60^{\circ}+\alpha^{\circ}}^{\alpha^{\circ}} E_{m} \cos \left(\omega t+30^{\circ}\right) d \omega t \\
& =\frac{3 E_{m}}{\pi} \cos \alpha \\
& =V_{d 0 r} \cos \alpha
\end{aligned}
$$


Except for firing delay, reduction of DC voltage is also caused by the leakage reactance of the transformer $\left(X_{c}\right)$. Also, commutation of the valves cannot be completed instantly due to the inductance of the transformer. Reduction of the DC voltage depends on reactance and direct current. As a result, it is required to include the effect of leakage reactance. It is shown in equation (2), where $V_{d r}$ is the DC voltage of the rectifier side, $V_{d 0 r}$ is the no-load DC voltage of the rectifier side, $X_{c}$ is the leakage reactance of the transformer, $I_{d}$ is the DC current.

$$
V_{d r}=V_{d 0 r} \cos \alpha-\frac{3}{\pi} X_{c} I_{d}
$$

In the same way for the rectifier side, the DC voltage of the inverter side can be represented as the equation (3), where $V_{d i}$ is the DC voltage of the inverter side, $V_{d 0 i}$ is the no-load DC voltage, $\gamma$ is the extinction angle. In the case of the inverter side, since the valves are connected reversely, the firing angle should have an angle between $90^{\circ}$ and $180^{\circ}$ while the extinction angle should have an angle between $0^{\circ}$ and $90^{\circ}$.

$$
V_{d i}=V_{d 0 i} \cos \gamma-\frac{3}{\pi} X_{c} I_{d}
$$

\subsection{Control of HVDC system}

In the CIGRE benchmark HVDC model, controllers of the HVDC system are composed of a rectifier controller and an inverter controller as shown in Figure 4. The rectifier controller is composed of a current controller. The maximum value of the output of the PI controller and the output for protection of DC line faults, $F_{\text {retard }}$, is decided as the firing angle of the rectifier side.

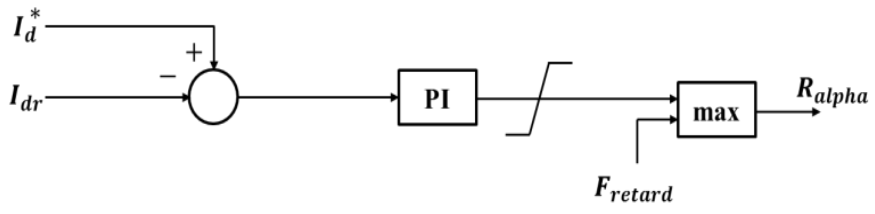

(a) The controller of the rectifier.

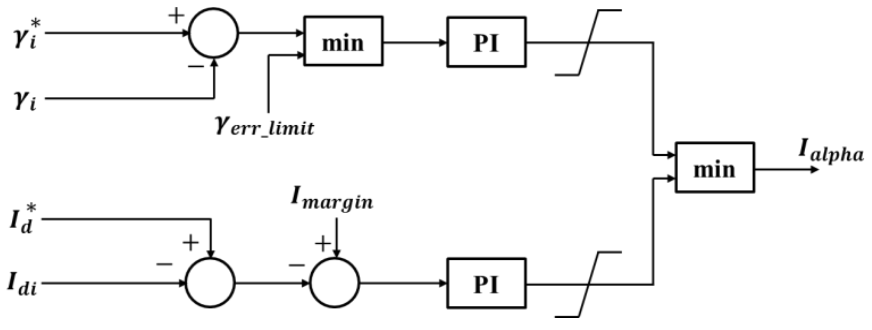

(b) The controller of the inverter side.

Figure 4. The Diagram of HVDC Control Loop

Both the current control and the gamma control are used for the inverter side. Particularly, the reference of the current control of the inverter side is different from the reference of the rectifier side. The current margin for the prevention of the crossing of the two characteristics is applied to the current control of the inverter side. In case of the gamma control, the 
excessive rise of the error between the measured gamma and the reference is limited by the minimum function.

\section{Implementation of HILS System}

In this paper, the plant is the CIGRE HVDC system and the subsystem is controllers of the rectifier and the inverter. In addition, the eMEGAsim RTDS supplied by OPAL-RT is adopted for the RTDS and a CompactRIO is used for the controllers of the rectifier and the inverter in this paper. Figure 5 shows the conceptual configuration of the developed HILS system for this study, where, the RT-LAB is a software program used to model the CIGRE HVDC system and to operate the HILS system.

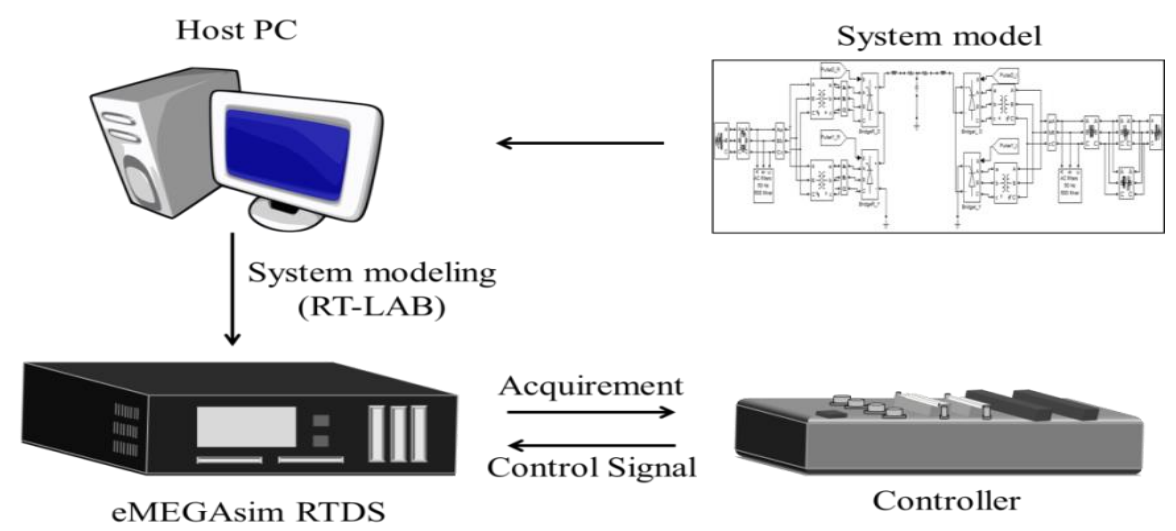

Figure 5. The Conceptual Configuration of the Developed HILS System

The eMEGAsim RTDS interfaces with the CompactRIO-based controllers through the data shield cables. The CompactRIO-based controllers acquire the data for the DC current of the rectifier side $\left(I_{d r}\right)$, the DC current of the inverter side $\left(I_{d i}\right)$, and the gamma angle of the inverter side $\left(\gamma_{i}\right)$. And then, the firing angles by the CompactRIO-based controllers are transmitted to the eMEGAsim RTDS, where $\alpha_{r}$ is the firing angle of the rectifier side, $\alpha_{i}$ is the firing angle of the inverter side. The signals flow between the eMEGAsim RTDS and CompactRIO-based controllers and program codes are represented in Figure 6 and Figure 7, respectively.

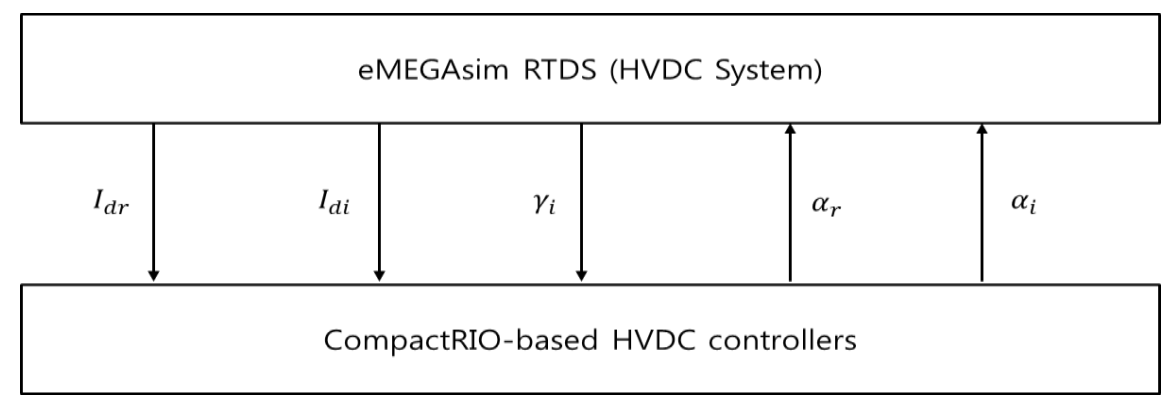

Figure 6. The Signal Flow between eMEGasim RTDS and CompactRIO-based Controllers 


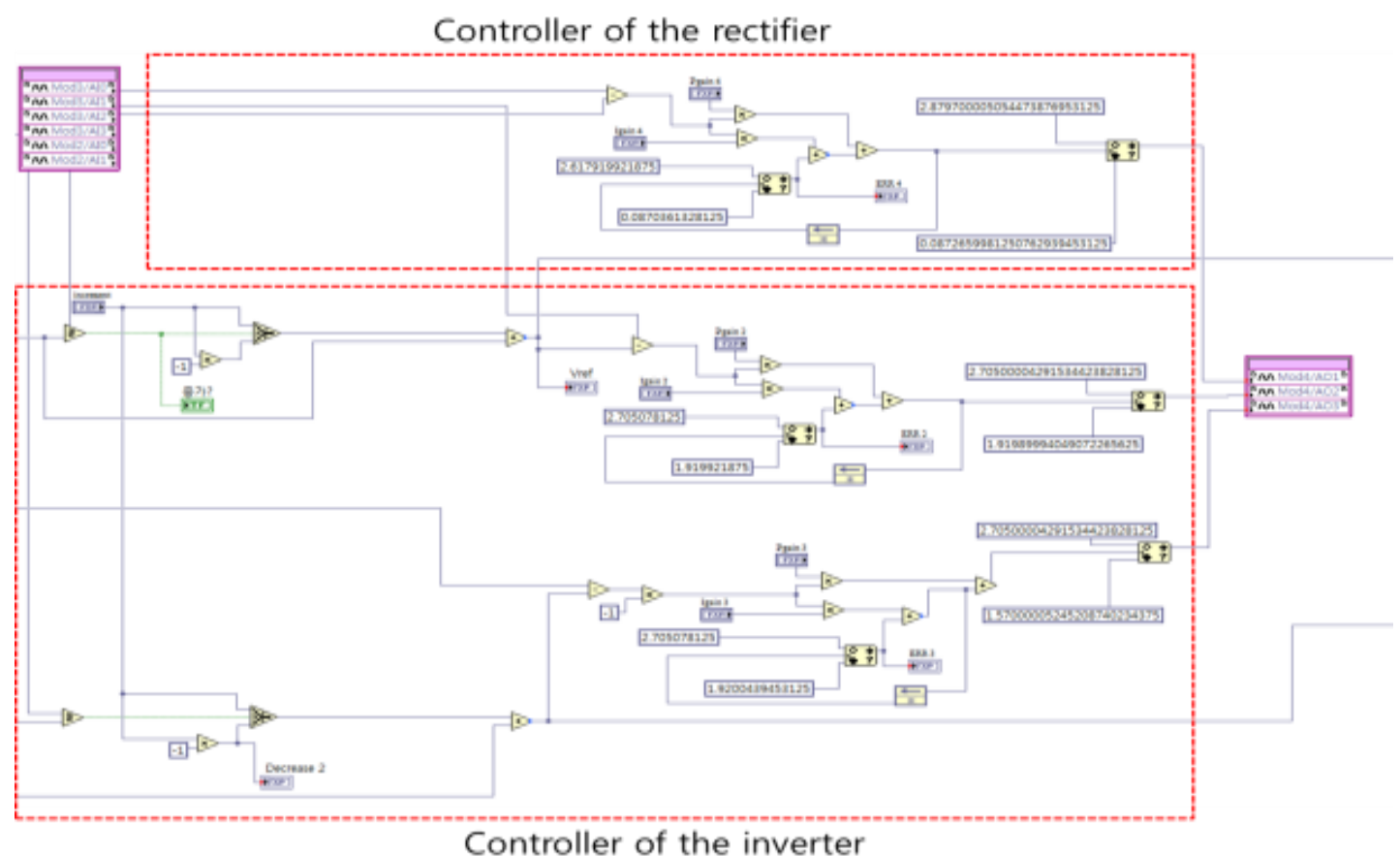

Figure 7. HVDC Controllers Designed by the LabVIEW

Figure 8 shows the HILS system implementing CIGRE benchmark HVDC system based on eMEGAsim RTDS and CompactRIO. In the HILS system, PC\#1 is used to design controllers of the HVDC system based on the LabVIEW. PC\#2 is the host PC of eMEGAsim RTDS in which the HVDC system except the controllers is modeled. As you can see, in this paper, the control parts are designed and implemented using the CompactRIO as a generalpurpose controller.

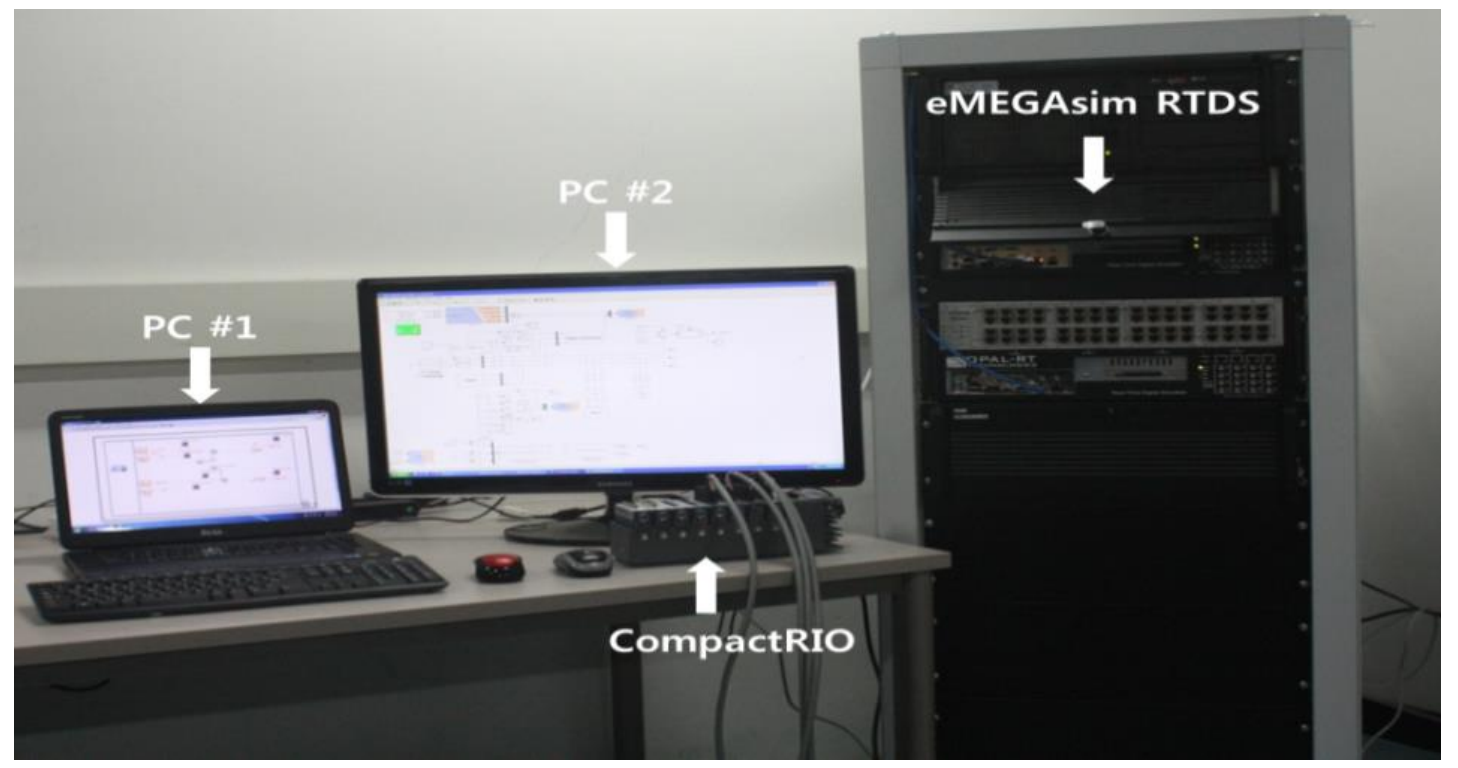

Figure 8. The Developed HILS System 


\section{Controller Test and Results}

In order to test control response of the HVDC system, the following scenarios are applied [19].

- $20 \%$ change of the current reference at the rectifier side

$\cdot 5^{\circ}$ change of the gamma reference at the inverter side

- $10 \%$ change of the current reference at the inverter side

\section{1. $20 \%$ change of the current reference at the rectifier side}

In order to test the response of the current controller at the rectifier side, $20 \%$ change of the current reference is applied by force. Figure 9 shows current and the firing angle at rectifier and inverter sides as a result. The current reference is decreased to $0.8 \mathrm{pu}$ at $1 \mathrm{sec}$ and is returned to $1 \mathrm{pu}$ at $1.5 \mathrm{sec}$. When the reference of current is changed, the firing angle is increased to decrease the DC current. Although constant gamma controller controls the DC voltage, the terminal voltage at the inverter side is increased due to the reduced voltage drop by the overlap. As a result, the firing angle is controlled at the somewhat reduced angle. Likewise, the firing angle at the inverter side is also increased due to the reduction of overlap angle. From the test result, we can see that the HVDC system is controlled well.

\section{2. $5^{\circ}$ change of the gamma reference at the inverter side}

Voltage is controlled by controlling the constant gamma reference. To evaluate the performance of the voltage controller by changing the gamma reference, the gamma reference of the steady state is increased from $15^{\circ}$ to $20^{\circ}$ at $1 \mathrm{sec}$ by force. This gamma reference is continued for $0.5 \mathrm{sec}$. Figure 10 shows the response characteristics the DC current at the rectifier side, DC voltage, gamma angle, and alpha angle at the inverter side when the gamma reference is changed by force. As shown in Figure 10, when the gamma angle is increased, the terminal voltage at the inverter side is decreased. However the DC current is maintained by the current controller at the rectifier side and the firing angle is decreased. As a result, the overlap angle is increased about $2.5^{\circ}$ due to the decrease of the firing angle. From the test result, we can see that the HVDC system is controlled well.

\section{3. $10 \%$ change of the current reference at the inverter side}

Figure 11 shows response characteristics of DC current and the firing angle at rectifier and inverter sides by $10 \%$ change of the current reference. In order to control DC current by the current controller at the inverter side, the firing angle is maintained as the minimum value by changing the minimum firing angle at the rectifier side to $26^{\circ}$ by force as shown Figure 11 (c). As shown in Figure 11 (b), the current reference of the inverter is decreased to $0.8 \mathrm{pu}$ at $1 \mathrm{sec}$, and then it is recovered to $0.9 \mathrm{pu}$. In addition, DC current is well controlled in approximately $100 \mathrm{~ms}$ during the $10 \%$ change of the current reference. The firing angle of the inverter is increased by the reduction effect of the overlap during the decrease of DC current as shown in Figure 11 (d). As a result, DC voltages of the rectifier and the inverter are increased by the increase of firing angle of the inverter. 
International Journal of Control and Automation

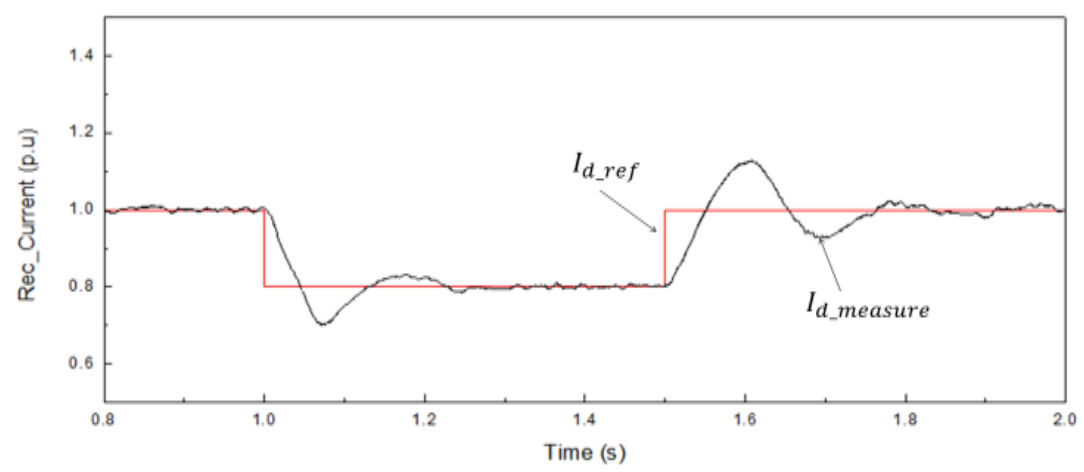

(a) Current of the rectifier side.

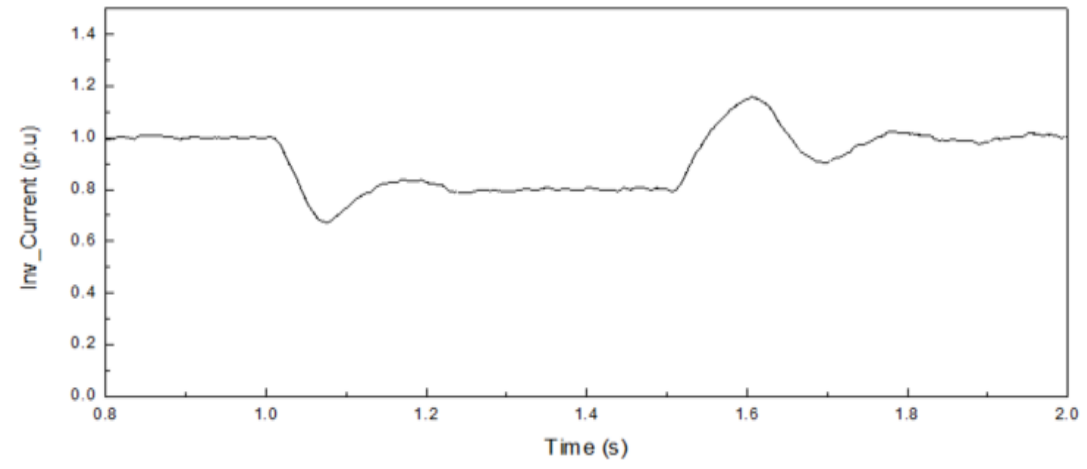

(b) Current of the inverter side.

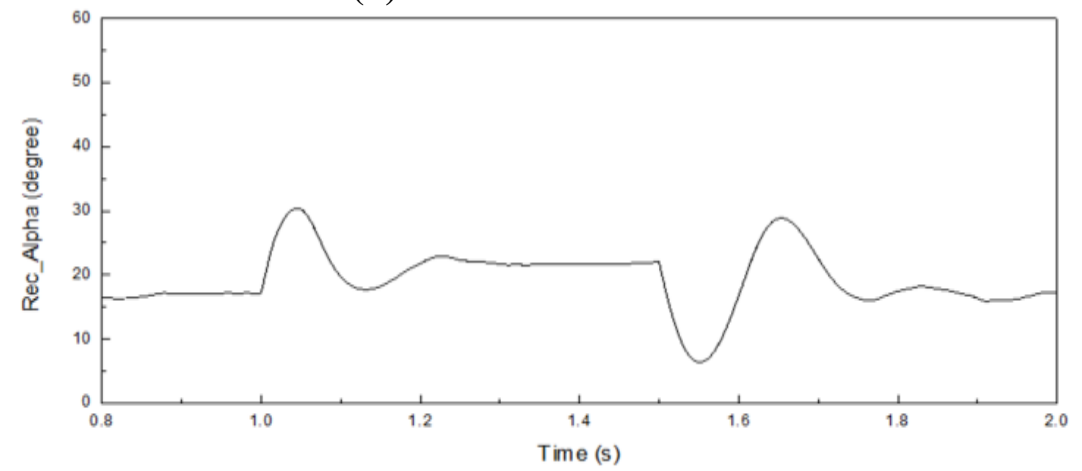

(c) The firing angle of the rectifier side.

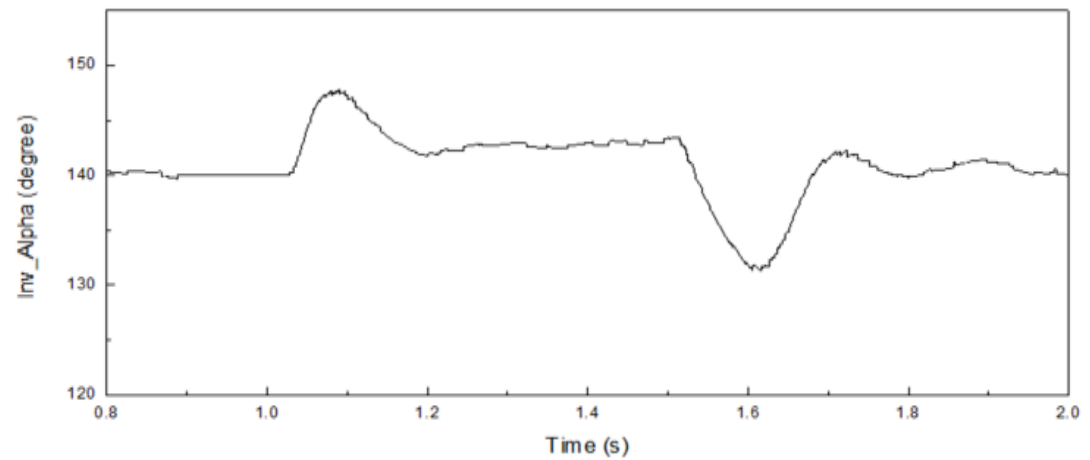

(d) The firing angle of the inverter side.

Figure 9. Response Characteristics by the Current Reference 


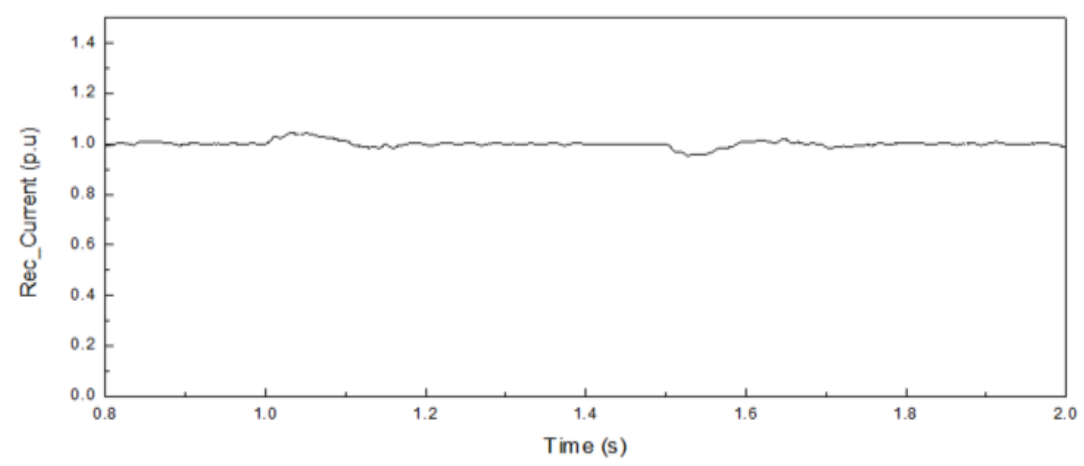

(a) Current of the rectifier side.

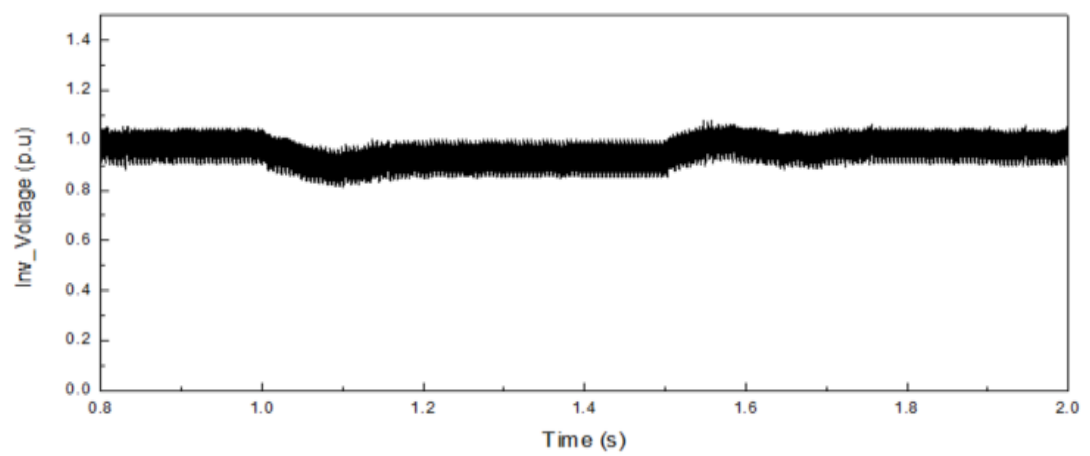

(b) Voltage of the inverter side.

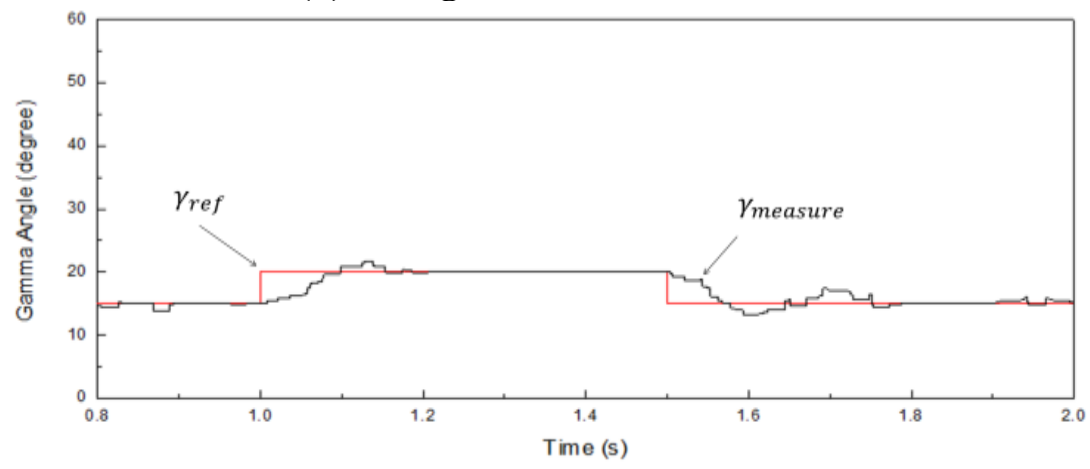

(c) The gamma angle of the inverter side.

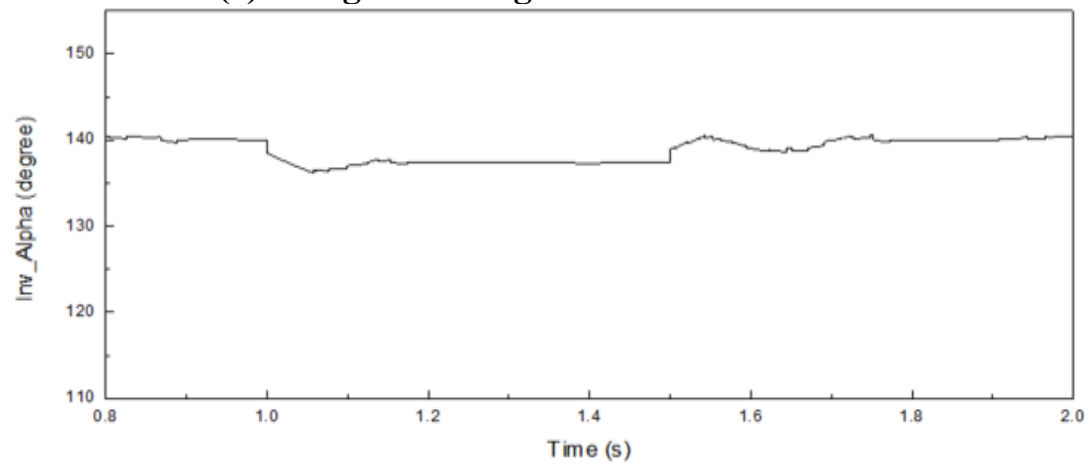

(d) The firing angle of the inverter side.

Figure 10. Response Characteristics by the Gamma Reference 
International Journal of Control and Automation

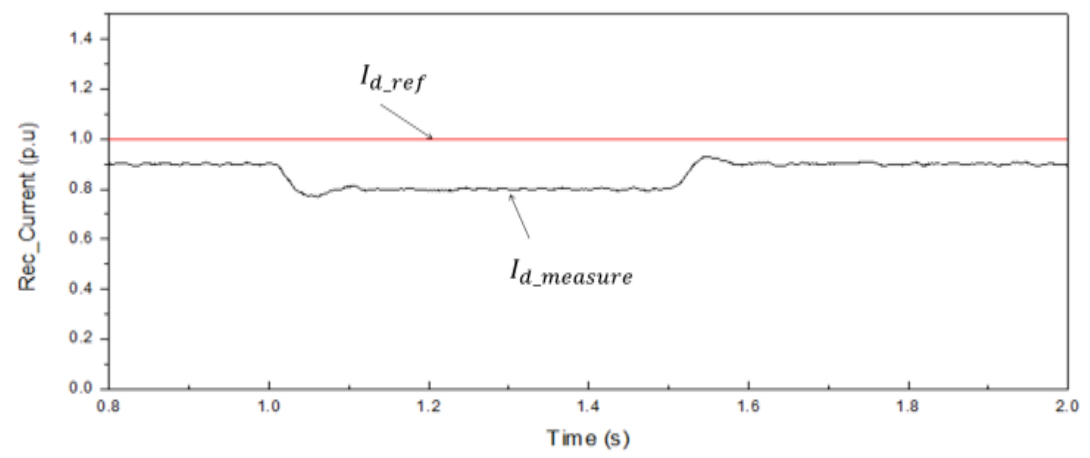

(a) Current of the rectifier side.

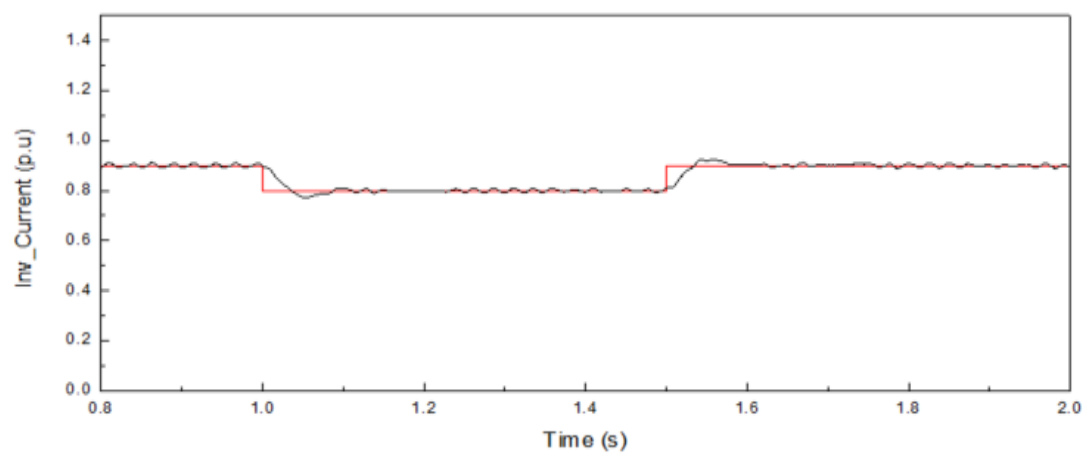

(b) Current of the inverter side.

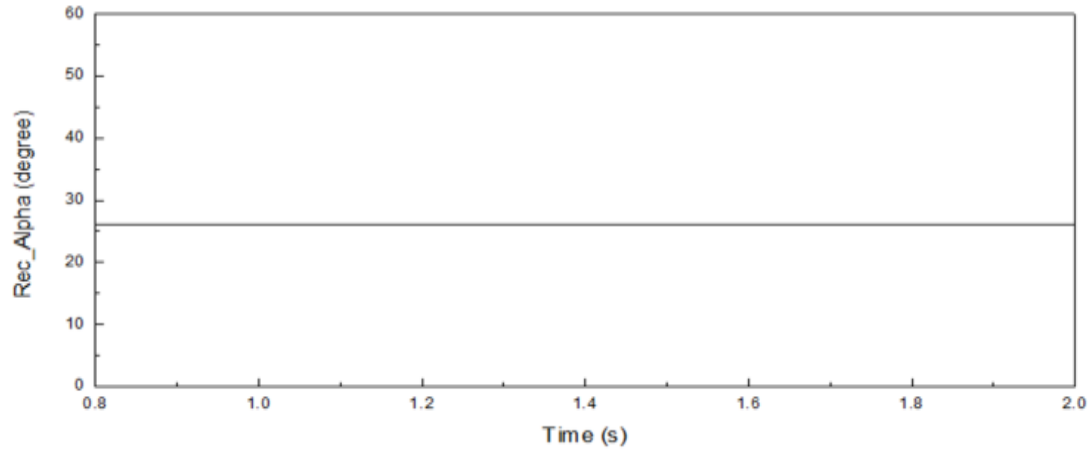

(c) The firing angle of the rectifier side.

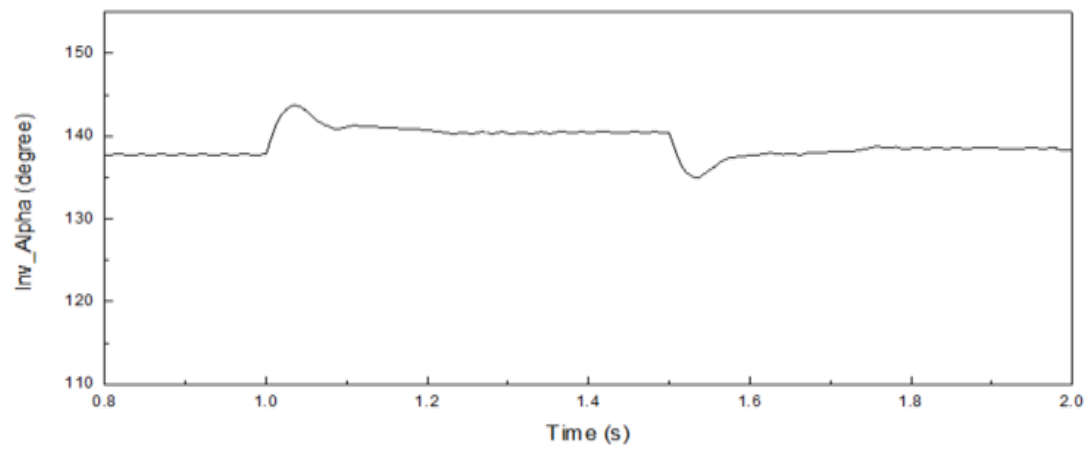

(d) The firing angle of the inverter side.

Figure 11. Response Characteristics by the Current Reference 


\section{Conclusion}

In this paper, a HILS system has been developed to test controllers of the CIGRE benchmark HVDC system in laboratory environment. The HVDC controllers has been designed using CompactRIO, a general-purposed controller and the HVDC system have been modeled using the eMEGAsim RTDS supplied by OPAL-RT to emulate the CIGRE benchmark HVDC system. The performance of developed controllers of the CIGRE benchmark HVDC system has been tested and the test results have been analyzed.

For the future work, the protective system of the CIRGE benchmark HVDC system will be designed and will be tested using the developed HILS system.

\section{References}

[1] K. Zhou, X. Fu, M. Cheng, X. Zhu, W. Wang, and T. Wang, "Topologies and Control of VSC-HVDC System for Grid Connection of Large-Scale Off-Shore Wind”, Proceedings of ICEMS, (2008), pp. 2357-2361.

[2] M. X. Bui, M. H. Nguyen, and T. K. Saha, "Dynamic Simulation of HVDC Interconnection in Large Power System", Proceedings of Power and Energy Society General Meeting, (2011).

[3] M. H. Abdullah, "Operational Performance of the Malaysia-Thailand 300/600 MW HVDC Interconnection", Proceedings of PECon, (2003), pp. 317-321.

[4] K. P. Basu, "Stability Enhancement of Power System by Controlling HVDC Power Flow through the Same AC Transmission Line”, Proceedings of ISIEA, vol. 2, (2009), pp. 663-668.

[5] M. Ramesh and A. J. Laxmi, "Stabilty of Power Transmission Capability of HVDC System using FACTS Controllers", Proceedings of ICCCI, (2012).

[6] T. Smed and G. Andersson, "Utilizing HVDC to Damp Power Oscillations", IEEE Trans. on Power Delivery, vol. 8, no. 2, (1993), pp. 620-627.

[7] R. Da Silva, R. Tedorescu, and P. Rodriguez, "Multilink DC transmission System for Surpergrid Future Concepts and Wind Power Intergration", Proceedings of RPG, (2011).

[8] P. Fairley, "Germany Jump-Starts the Supergird", IEEE Spectrum, vol. 50, no. 5, (2013), pp. 36-41.

[9] J. H. Jeon, J. Y. Kim, H. M. Kim, S. K. Kim, C. H. Cho, J. M. Kim, J. B. Ahn, and K. Y. Nam, "Development of Hardware In-the-Loop Simulation System for Testing Operation and Control Functions of Microgrid", IEEE Trans. on Power Electron., vol. 25, no. 12, (2010), pp. 2919-2929.

[10] C. H. Yoo, W. J. Cho, I. Y. Chung, D. J. Won, S. S. Hong, and B. J. Jang, "Hardware-in-the-Loop Simulation of DC Microgrid with Multi-Agent System for Emergency Demand Response”, Proceedings of Power and Energy Society General Meeting, (2012).

[11] A. K. Parwal, G. Parwal, A. Sharma, and M. A. Khan, "Implementation of Fuzzy Technique Based on LabVIEW for Control Gas System Using USB 6009”, International Journal of Control and Automation, vol. 6, no. 3, (2013), pp. 365-374.

[12] B. Lu, X. Wu, H. Figueroa, and A. Monti, “A Low-Cost Real-Time Hardware-in-the Loop Testing Approach of Power Electronics Controls”, IEEE Trans. on Power Electron., vol. 54, no. 2, (2007), pp. 919-931.

[13] S. H. Kim, M. C. Chin, and C. N. Chu, "Development of EHPS Motor Speed Map Using HILS Sytem", IEEE Trans. on Vehicular Technology, vol. 62, no. 4, (2013), pp. 1553-1567.

[14] J. Du, Y. Wang, C. Yang, and H. Wang, "Hardware-in-the-Loop Simulaltion Approach to Testing controller of Sequential Turbocharging System", Proceedings of IEEE International Conference, (2012), pp. 2426-2431.

[15] J. M. Cho, D. H. Hwang, K. C. Lee, J. W. Jeon, D. Y. Park, Y. J. Kim, and J. S. Joh, "Design and Implementation of HILS System for ABS ECU of Commercial Vehicles", Proceedings of ISIE, vol. 2, (2001), pp. 1272-1277.

[16] J. W. Jeon, G. A. Woo, and K. C. Lee, "Real-Time Test of Aircraft Brake-by-Wire System with HILS \& Dynamometer System", Proceedings of IEEE Mechatronics, (2004), pp. 322-327.

[17] P. Kundar, Power System Stability and Control, McGraw-Hill, New York (1993).

[18] W. Nenille and A. Jos, Power Systems Electromagnetic Transients Simulation, IEE, London, UK (2003).

[19] V. K. Sood, HVDC and FACTS Controllers, Kluwer Academic Publishers, Boston (2004). 


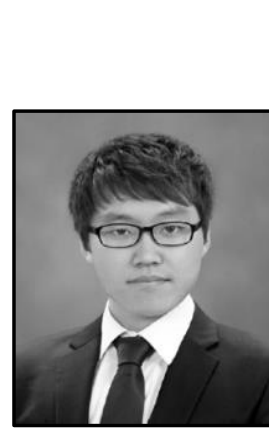

\section{Authors}

Ho-Ik Son, he received his B.S degree in electrical engineering from Incheon National University, Korea in 2012. Currently he is a combined master and $\mathrm{Ph}$. D. student in Electrical Engineering from Incheon National University. His research interests are power system analysis and HVDC system control

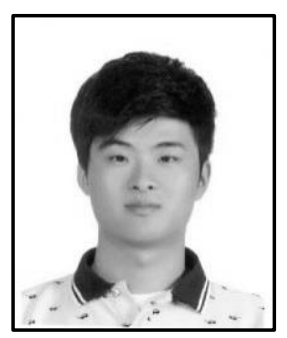

Hyeong-Jun Yoo, he received his M.S degree in Electrical Engineering from Incheon National University, Korea in 2014. Currently he is a Ph. D. student in Electrical Engineering from Incheon National University. His research interests are microgrid, VSC control, MMC HVDC, power conversion.

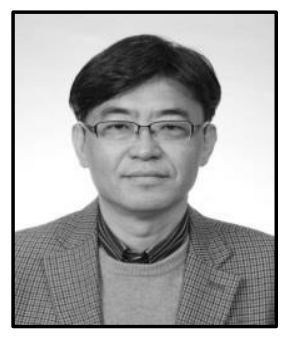

Hak-Man Kim, he received his $\mathrm{Ph}$. D. degree in Electrical Engineering from Sungkyun-kwan University, Korea in 1998 and received his second $\mathrm{Ph}$. D. degree in Information Sciences from Tohoku University, Japan in 2011. He worked for Korea Electrotechnology Research Institute, Korea from Oct. 1996 to Feb. 2008. Currently he is a professor in the Department of Electrical Engineering, Incheon National University, Korea. His research interests include power system analysis \& modeling, HVDC, FACTS, ESS, and microgrid. 